\title{
THE EFFECT OF SLEEP ON SKIN TEMPERATURE REACTIONS IN
} A CASE OF ACROCYANOSIS

\author{
BY RICHARD DAY AND WALTER O. KLINGMAN \\ (From the Normal Child Development Study of the Department of Diseases of Children, and \\ the Department of Neurology, Columbia University, and the Babies Hospital, \\ New York City)
}

(Received for publication January 9, 1939)

Acrocyanosis is a condition in which the extremities are cold and blue. It differs from Raynaud's disease in that it does not occur in attacks, but is relatively permanent, and in that there is no sharp line of demarcation separating the normal skin from the abnormal areas. Lewis and Landis (1) believe that the fault lies in an excessive sensitivity to cold on the part of the small vessels of the extremities. This sensitivity results in spasm of the arterioles and a secondary dilation of the venous capillaries. Villaret and coworkers (2) and Kreindler and Elias (3) believe that the cause is hypertonicity of the sympathetic nervous system. Elliott, Evans, and Stone (4) emphasize chiefly a local fault of the small vessels, but they recognize that centrally arising impulses may be contributory. They feel that there is merely dilation and atonicity of the venules and venous capillaries rather than spasm of the arterioles. Pearse (5) believes that in Raynaud's disease sensitivity of the vessels causes an exaggerated vascular response to normal influences, whether local or general.

It is the purpose of this paper to describe a study of the spontaneous warming of the hands and feet in sleep in a case of acrocyanosis. The facts collected lend support to the theory that the condition in this case may be the result of vasoconstrictive influences arising from central portions of the sympathetic nervous system and not directly related to the temperature of the environment.

\section{CASE HISTORY}

The patient, M. L. (Babies Hospital Number 546,672), was a 61/2-year-old girl of Russian Jewish parentage. A sibling who had died and a cousin who was otherwise well had cold hands and feet. Our patient had suffered from a predominating coldness and blueness of her hands and feet since the age of six months, with partial relief in the summer but with complete relief at all seasons during sleep. She also had periodic episodes of unex- plained vomiting lasting two or three days, which were the occasions for her two admissions to the hospital. Abnormal physical findings at $61 / 2$ years of age were confined to the skin. The hands and feet felt very cold. The hands were cyanotic, being about VIII to $\mathrm{X}$ on Lewis' scale (6). They were slightly damper than normal. The feet were less affected than the hands. The abnormal skin of the hands and feet merged gradually with that of the normal legs and forearms. The remainder of the skin was normal except for irregular red areas which appeared when the child had cried hard for a few minutes. They would appear all over the body and resembled, except in distribution, an ordinary blush. The blood pressure was $105 / 70$, pulse 90 , and respirations 20 per minute. The I.Q. was 70 on the StanfordBinet scale, and there was definite emotional instability.

Blood counts, urine analyses, Mantoux test, and blood $\mathrm{Kahn}$ test were normal. X-rays showed no cervical ribs. During one of her vomiting episodes, $x$-rays following a barium meal were taken, and Dr. John Caffey's report states, "Roentgen findings demonstrate complete pyloric obstruction for 3 hours and gastric retention of considerable amount at $63 / 4$ hours." That this obstruction resulted from spasm is indicated by the complete disappearance of this block when roentgen examination was repeated. The child had no digestive symptoms while in the hospital, and further investigation was confined to a study of skin temperatures.

\section{SPECIAL OBSERVATIONS}

Measurements of the rectal and skin temperatures were made under various circumstances. For the skin temperatures, a thermocouple was used which was accurate to about $0.5^{\circ} \mathrm{C}$. Rectal temperature was continuously recorded by a nickel resistance thermometer, accurate to $0.1^{\circ} \mathrm{C}$.

The prompt rise in finger and hand temperature following the onset of normal sleep is shown in Figure 1. The cheek cooled off slightly. The rectal temperature rose slightly during the first part of the observation, and then remained constant. In Figure 2 there is shown the equally prompt cooling of the fingers and hand when the patient awoke from normal sleep. The child had gone to sleep with mittens on. The right hand 


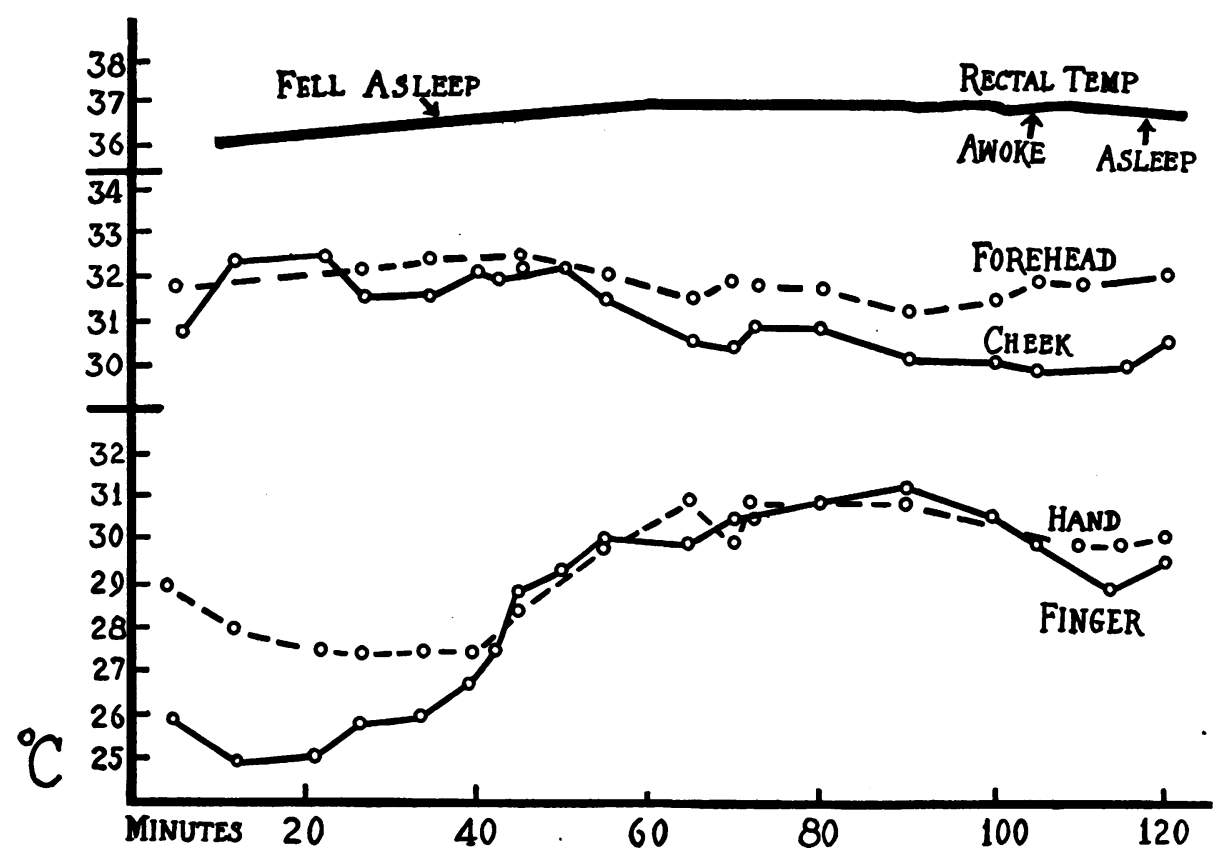

Fig. 1. Rapid Rise in the Skin Temperature of the Hand and Finger Following THE ONSET of Normal SLeEp

The room temperature varied between $22.8^{\circ} \mathrm{C}$. and $23.3^{\circ} \mathrm{C}$. The child was dressed in a single cotton garment, and was covered, except for the parts measured, with a cotton sheet.

mitten was removed at the beginning of the observation. The left hand mitten was kept on except momentarily for the three observations recorded on the chart, thus maintaining the same thermal environment as had been present during sleep. The elevation of skin temperature in sleep was accompanied by a change in color to a deep red which, upon awakening, was again rapidly replaced by cyanosis.

These observations suggest that in this case of acrocyanosis there is, during the waking state, a

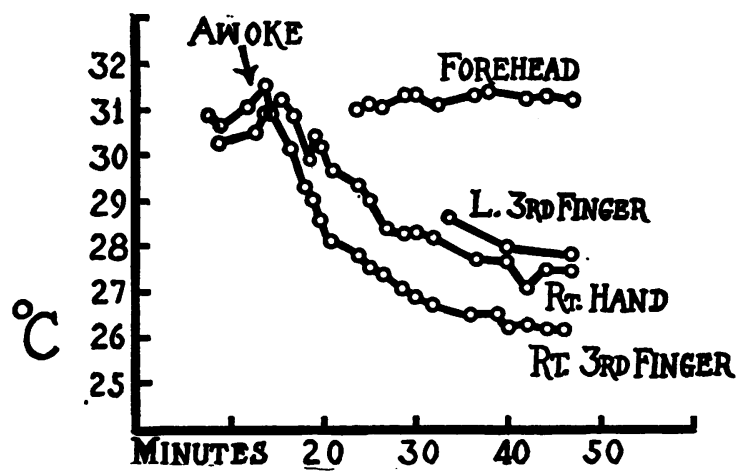

Frg. 2. Fall in Skin Temperature of the Hands aNd Fingers Occurring Upon Awakening vascular spasm which results from central impulses rather than from local conditions and that these impulses are in abeyance during sleep. To test this further, observations were made on the reactions to various thermal conditions, both local and general, when the subject was awake and when she was asleep. The results are shown in Figures 3, 4, and 5.

In Figure 3, sleep was induced by 0.240 gram of sodium phenobarbital. After the initial rise in temperature of the finger and hand, the palm of the hand was placed in contact with a cake of ice for a period of 10 minutes ( $A$ in Figure 3 ). Although the temperature of the palm of course fell (to $25^{\circ} \mathrm{C}$.), the dorsum of the hand showed only a slight fall, and there was no change in color. After the ice was removed $(B)$ both feet were placed in tepid water $(C)$, which was then raised to about $43^{\circ} \mathrm{C}$. The water was then cooled, at first slowly, and then rapidly to $18.9^{\circ} \mathrm{C}$. $(E)$. The foot bath was removed at $F$. The skin temperature of the finger, hand, and arm as well as the rectal temperature showed fluctuations during these variations in the foot bath temperature. In fact, the fall in rectal temperature induced by the 


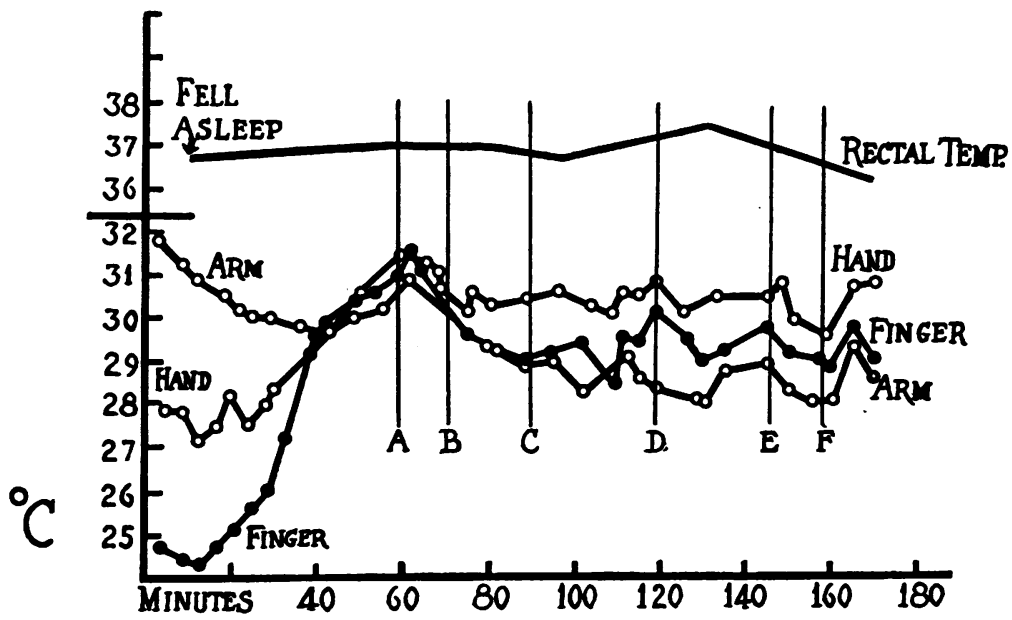

Fig. 3. Effect of Various Thermal Situations Tested White the Child Was Asleep Under the Influence of 0.240 Gram of PhenoBARBITAL

The room temperature varied between $21.6^{\circ} \mathrm{C}$. and $22.7^{\circ} \mathrm{C}$. and the child was dressed in a single cotton garment. For explanation of the procedures, see text.

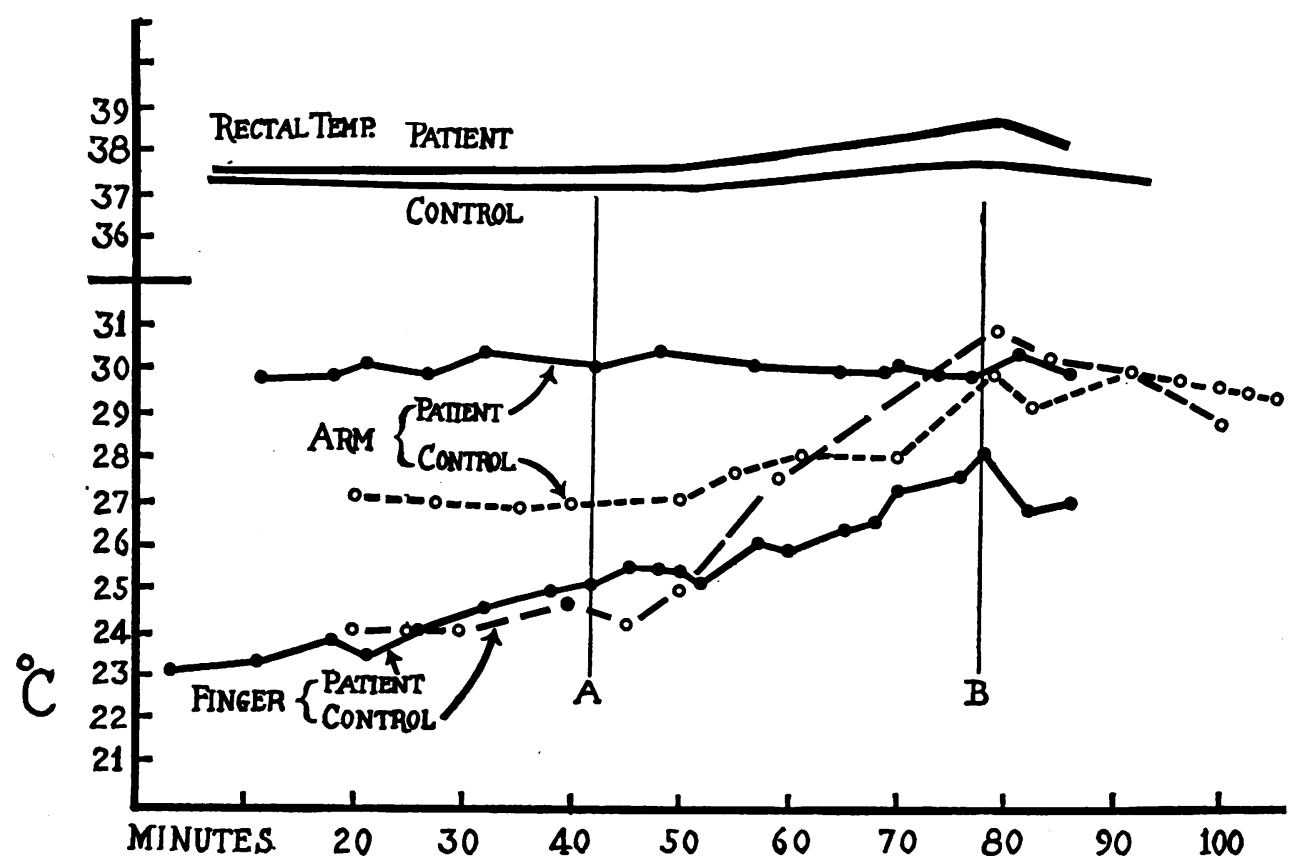

Fig. 4. Pattent's Reaction (While Awake) to a Warm Foot Bath as Compared With That of a Normal Child

The room temperature was $23^{\circ} \mathrm{C}$. for the patient, and slightly cooler $\left(21^{\circ} \mathrm{C}\right.$.) for the control, in order to bring the skin temperature of the latter down to a level comparable with the patient's. At $A$, the feet were put in a warm foot bath (about $42^{\circ} \mathrm{C}$.) and removed at $B$. 


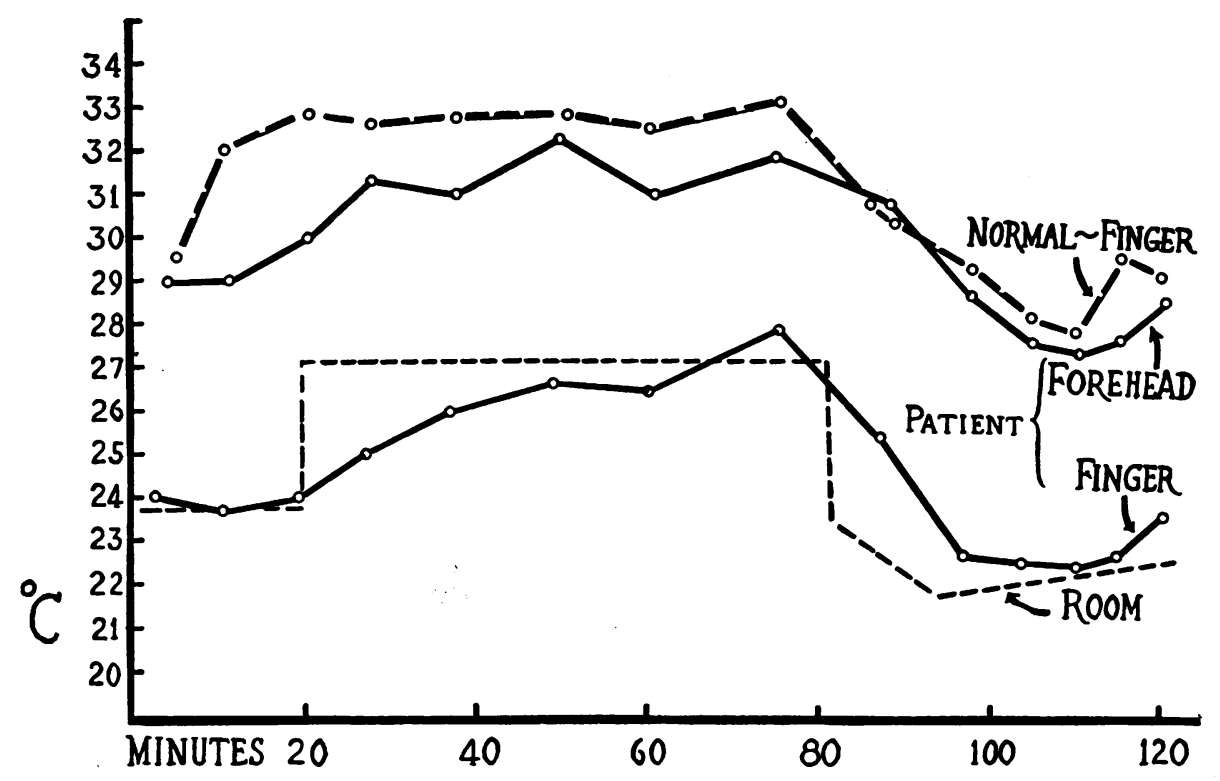

Fig. 5. The Effect on Skin Temperature of Moving the Patient and a Normal Control from a Cold to a Warm Room, and Back Again

The room temperature is shown by the dash line. The control was an adult who was dressed in ordinary clothes, and the patient had on two simple one-piece cotton garments. The patient's finger did not deviate much from the room temperature. The amount of rise and fall in skin temperatures was about the same in the two subjects.

cool foot bath amounted to $1^{\circ} \mathrm{C}$. in 35 minutes. However, it should be noted that the temperature of the hand and finger varied in a parallel fashion with that of the upper arm, although the latter area was not involved in the cyanotic condition. Both constricting and dilating influences, then, are responded to by the hand in the same way as by the skin of the arm, so long as the patient is asleep. These reactions could be tested only after phenobarbital because in normal sleep the procedures awakened the patient. Even a short period of wakefulnes has an effect on skin temperature, as is shown in the last portion of the graph in Figure 1.

When the patient was awake, the hand responded sluggishly to dilating influences. A standard test of autonomically mediated vasodilatation consists in noting the elevation of skin temperature of the extremity to be examined in response to heat applied to the body by, for example, a warm foot bath. Figure 4 shows the results of such a test in this patient, in comparison with a normal child. The procedure produced a delayed and incomplete vasodilatation. Figure 5 shows the response obtained by moving the pa- tient and a control subject (a normal adult) from a cool room to a warm room and back again. It is seen that quantitatively, the rise in skin temperature was about the same in the two subjects, and about the same as the rise in the environmental temperature. Again, however, the patient showed a sluggish response. These two observations suggest that when the patient is awake, dilating influences in response to the demands of thermal regulation can occur, but they are sluggish, as though hindered by the persistent vasoconstriction that is present when the patient is awake. In the summer, it was likewise noted clinically in our patient that although the hands were warmer than in the winter, they were nevertheless at all times cooler than those of normal children.

It was noticed that during the observations made while the foot bath was being used the rectal temperature of the patient seemed more labile than that of the control subjects. To quantitate this observation, however, a larger series of normals would be required.

In order to speculate intelligently as to the nature of the constricting influences which in this patient are abolished by sleep, a better knowledge 
of normal physiological changes in sleep would be required.

\section{ACTION OF DRUGS}

The following drugs had no detectable influence on skin temperature or color of the hands in our patient: papaverine hydrochloride $(15 \mathrm{mgm}$. intravenously); padutin ( 0.25 cc. intramuscularly); atropine sulphate $(0.3 \mathrm{mgm}$. subcutaneously); ergotamine tartrate $(0.07 \mathrm{mgm}$. subcutaneously). On two other occasions ergotamine tartrate seemed to be the cause of a rise of $3^{\circ} \mathrm{C}$. in the skin temperature of the hand but that could not be repeated later. Syntropan (16 mgm. by mouth) had no effect.

The inhalation of amyl nitrite was followed by a rise of $1^{\circ} \mathrm{C}$. for a few minutes.

Histamine iontophoresis was applied to one hand. A 1 per cent histamine ointment was used, and a current of 1000 milliampere seconds. The skin temperature rose from $25^{\circ} \mathrm{C}$. to $29^{\circ} \mathrm{C}$., and the color of the hand became a deep red. Within an hour after the treatment, however, the temperature had fallen to $27^{\circ} \mathrm{C}$., and the cyanotic color had returned.

\section{OTHER OBSERVATIONS}

Microscopic observation of the capillaries of the nail bed showed considerable dilation on the venous side, and very little flow of blood.

Elevation of the arm caused a paling of the hand in about 15 seconds. The paling was less marked than the descriptions in Lewis' and in Elliott's papers would indicate occurred in their cases. It was sufficient, however, to provide good evidence against venous block.

Placing the hand in water at $40.5^{\circ} \mathrm{C}$. changed the color of the hand to a deep red. This test suggested that local heat in this case could bring about dilation and a flow of blood. The depth of color provided further evidence that the venous capillary bed was dilated. Such dilation would be in accord with the capillary microscopic findings, and with the observations of both Lewis and Elliott.

When the patient was emotionally upset, as in a temper tantrum, red blotches appeared over her whole body. These were from $1^{\circ} \mathrm{C}$. to $3^{\circ} \mathrm{C}$. higher in temperature than the surrounding skin.
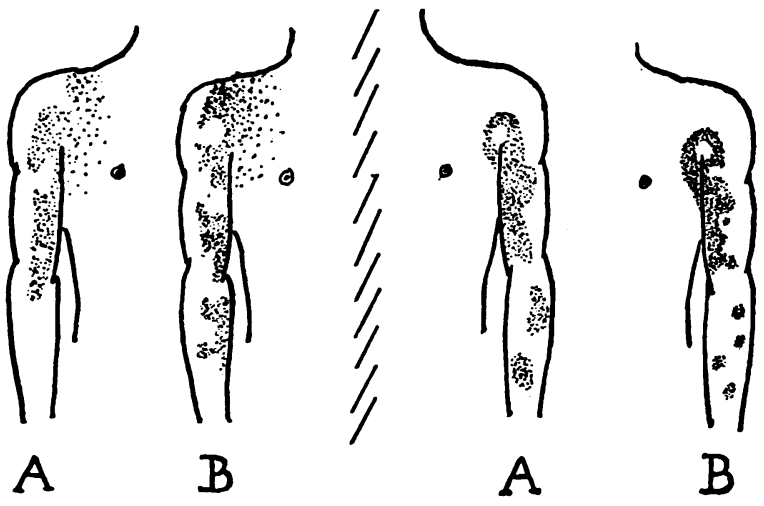

B

Fig. 6. Distribution of Warm Red Areas on the ARMS

These would appear during temper tantrums, and the pattern assumed by the red areas would often, but not always, be repeated with each episode of crying. The diagram at $A$ was drawn during a temper tantrum three days before the one at $B$.

Furthermore, as the diagram of the arms in Figure 6 shows, the involved areas had a pattern which was often reproduced in a rough way on different days. On other occasions, this pattern would assume new forms. Some widespread disorder of the sympathetic vasomotor system would be required to explain this observation. The pyloric spasm noted on $\mathrm{x}$-ray examination might well have been sympathetic in origin, also.

\section{SUM MARY}

A case of acrocyanosis in a $61 / 2$-year-old girl is described. In sleep, her hands and feet became warm and red; and under these conditions the hands responded in a parallel way with the rest of the body to warm and cold foot baths. Local cooling of the palm of the hand did not induce vasoconstriction when she was asleep. Microscopic observation of the capillaries at the base of the nails showed sluggish flow of blood and dilation of the venous side. These observations seem to support the contention of Lewis that in acrocyanosis the primary fault is vasoconstriction of the arterioles. However, the predominant influence of sleep over thermal influences on the condition of this patient's hands points to abnormal vasomotor tone of central origin as the primary cause, rather than local sensitivity to cold such as was demonstrated in their cases by Lewis and by Pearse. Further evidence of sympathetic 
nervous system dysfunction was noted in a peculiar blotchiness of the skin during spells of anger. Spasm of the pylorus, which was demonstrated radiologically on one occasion, constituted a possible cause of her periodic episodes of vomiting, and presented further evidence of widespread sympathetic abnormality.

We wish to thank Dr. I. Shulman of the Department of Pharmacology for the capillary microscopic examination, and Dr. Robert Muller of the Physical Therapy Department of the Presbyterian Hospital for doing the histamine iontophoresis. We are also grateful to Dr. Beverly Smith for valuable criticism.

\section{BIBLIOGRAPHY}

1. Lewis, T., and Landis, E. M., Vascular mechanisms in acrocyanosis. Heart, 1930, 15, 229.
2. Villaret, M., Justin-Besançon, L., Cachera, R., and Boucomont, R., Etude critique sur la pathogénie des troubles circulatoires periphériques. Premiere Partie: Les Acrocyanoses. Arch. d. mal. du coeur, 1934, 27, 725.

3. Kreindler, A., and Elias, H., Zur Klinik und Pathogenese der juvenilen Akrocyanose. Ztschr. f. Kinderh., 1930-31, 50, 608.

4. Elliott, A. H., Evans, R. D., and Stone, C. S., Acrocyanosis: A study of the circulatory fault. Am. Heart J., 1936, 11, 431.

5. Pearse, Herman E., The influence of the heat regulatory mechanism on Raynaud's disease. Am. Heart J., 1935, 10, 1005.

6. Lewis, T., Experiments relating to the peripheral mechanism involved in spasmodic arrest of circulation in fingers; variety of Raynaud's disease. Heart, 1929-31, 15, 7. 